\title{
ERRATA, VOLUME 51
}

Eric Reissner, Solution of a class of singular integral equations.

p. 921, equations (10), (11). For " $\sum_{m=1}^{\infty}$ " read " $\sum_{m=0}^{\infty}$."

p. 921, equation (12). For " $\sum_{m=1}^{2 N+1}$ " read " $\sum_{m=0}^{2 N+1}$."

\section{ERRATA, VOLUME 57}

New Publications. p. 408, line 7. For "Trans. by F. Prihonsky”" read "Ed. by F. Prihonský. Trans. by D. A. Steele." 